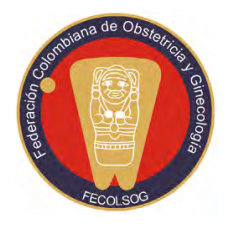

Revista Colombiana de Obstetricia y Ginecología Vol. 71 No. 4 • Octubre-Diciembre $2020 \bullet$ (323-344)

\title{
PRÁCTICAS INSTITUCIONALES EN SALUD EN MATERNAS SEGÚN CLASE SOCIAL. BOGOTÁ, COLOMBIA, 2018
}

\section{Institutional practices in maternal health according to sociall class. Bogotá, Colombia, 2018}

Libia Amparo Bedoya-Ruiz, M.D., M. Sc., Ph.D. ${ }^{I}$; Andrés Alonso Agudelo-Suárez, D.D.S., M. P. H, Ph.D. ${ }^{2}$; Diego Alveiro Restrepo-Ochoa, Psic, M.Sc., Ph.D. ${ }^{3}$; Santiago Henao-Villegas, M. V., M.Sc., Ph. D. ${ }^{4}$

Recibido: 27 de febrero de 2020/Aceptado: 31 de agosto de 2020

\section{RESUMEN}

Objetivo: comprender las prácticas institucionales en salud que se realizan en las mujeres en embarazo parto y posparto, según la clase social, en Bogotá. Materiales y métodos: estudio cualitativo, desde el paradigma de la hermenéutica crítica. Método de etnografía crítica, con muestreo teórico. Participaron 9 mujeres y 8 profesionales de la salud de la ciudad de Bogotá, que asistieron a instituciones públicas y privadas, pertenecientes a los regímenes subsidiado y contributivo del Sistema General de Seguridad Social en Salud (SGSS). Se realizaron 38 entrevistas a profundidad durante 13 meses y 62 acompañamientos a las maternas en las actividades

* Correspondencia: Libia A. Bedoya-Ruiz, Escuela de Graduados, Universidad CES, Calle 10 A, No. 22-04. Campus Poblado. Teléfono (+574) 44405 55, ext. 1963, Medellín (Colombia). bedoya. libia@uces.edu.co / bedoyalibia@hotmail.com

1 Doctora en Salud pública, Escuela de graduados; doctorado en Salud Pública Universidad CES, Medellín (Colombia).

2 Doctor en Salud Pública, Escuela de Graduados, Universidad CES, Medellín (Colombia). Profesor titular, Facultad de Odontología, Universidad de Antioquia, Medellín (Colombia). Investigador Senior Colciencias.

3 Doctor en Salud Pública. Profesor titular, Universidad CES, Medellín (Colombia). Presidente, Asociación Colombiana de Facultades de Psicología.

4 Doctor en Bioética. Profesor titular, Universidad CES, Medellín (Colombia). de control prenatal, vacunación, trabajo de parto, consulta posparto, exámenes de seguimiento, curso psicoprofiláctico, hospitalización y sala de espera, tanto en servicios públicos como privados. Análisis por triangulación en Atlas Ti.

Resultados: teniendo en cuenta los discursos de los actores, la observación participante y el contexto, se encontraron dos categorías que determinan estas inequidades, denominadas el mercado regula la salud, y la vigilancia y el control en los servicios de salud.

Conclusiones: en la práctica médica es conveniente fortalecer las competencias ciudadanas para garantizar los derechos del personal de salud y de las mujeres. Estudiar desde la investigación cualitativa es una oportunidad para promover la transformación de las racionalidades médicas que afectan a las mujeres.

Palabras clave: clase social, embarazo, parto, periodo posparto, medicalización.

\section{ABSTRACT}

Objective: To understand institutional practices in healthcare as relates to women during pregnancy, childbirth and the postpartum period according to social class in Bogota. 
Materials and methods: Qualitative study based on the critical hermeneutics paradigm. Critical ethnographic method with theoretical sampling. The participants included 9 women and 8 healthcare professionals from the city of Bogotá, attending public and private healthcare institutions that serve populations under both the subsidized as well as the contributive regimes of the General Social Security System. Overall, 38 in-depth interviews were conducted during a 13-month period, with 62 instances of support to the mothers in terms of prenatal care, vaccination, labor, postpartum visits, follow-up tests, psychoprophylactic course, hospitalization and waiting room. Triangulation analysis on Atlas Ti.

Results: Taking into account the discourse of the different players, observations and context, two categories were found to be determining factors of inequities: "Market-regulated health" and "Oversight and control in health services".

Conclusions: It is advisable in medical practice to build competencies in the population in order to ensure the realization of the rights of women and healthcare personnel. Qualitative research offers the opportunity to promote the transformation of medical rationale affecting women.

Key words: Social Class, Pregnancy, Childbirth; Postpartum Period, Medicalization.

\section{INTRODUCCIÓN}

Fernández define las prácticas institucionales en salud (PIS) como un "conjunto de estructuras organizativas" orientadas a la prestación de servicios de salud que integran "acceso, atención, educación, saberes, quehacer profesional, actividades, equipos, técnicas, y formación de recurso humano en derechos" (1).

A nivel mundial se ha evidenciado que existen ciertas PIS que afectan los derechos de las mujeres en embarazo, parto y posparto (EPP); algunas de estas no son recomendadas por la evidencia científica en condiciones de bajo riesgo, por lo que su aplicación en este grupo de gestantes podría llevar a la llamada violencia obstétrica (2-6). Este término incluye experiencias de procedimientos invasivos no consentidos que ocurren de forma rutinaria durante el parto (7), y el irrespeto y abuso durante este $(2,8)$.

$\mathrm{Al}$ respecto, se ha informado que en algunas regiones de Colombia aún se utilizan prácticas que cabrían en esta definición, tales como: la maniobra de Kristeller y la episiotomía de rutina $(9-12,13)$, los tactos vaginales no consentidos o por horario (9-11, 13-15), la ruptura artificial de membranas $(9,10$, 12, 13), la inducción artificial del parto $(9,10,12$, 13, 15), el pujo dirigido $(9,12-14)$, la prohibición de comer, beber y movilizarse durante el trabajo parto (9, 10, 12-15); intervenciones médicas de estudiantes sin consentimiento de la gestante $(9-12,14)$, prohibición de la entrada del acompañante $(9-11,14,15)$, bloqueo del apego madre-hijo $(9,10,12)$, aislamiento e incomunicación de la parturienta mientras se está en sala de partos $(9,10,12,14,15)$, entre otras. En algunos servicios de salud públicos se realizan historias clínicas conjuntas sin confidencialidad, existe insuficiencia de camas en el posparto que obligan a las mujeres a compartir camas, y los familiares deben esperar o dormir afuera de la institución (10).

La clase social se define como "el conjunto de sujetos organizados alrededor de intereses comunes" (16) que "se diferencian entre sí por el lugar que ocupan en un sistema de producción determinado, por las relaciones en que se encuentran frente a los medios de producción, por el papel que desempeñan en la organización del trabajo y, por consiguiente, por el modo y la proporción en que perciben la parte de la riqueza social de que disponen" (17). Esta es una categoría relevante en salud pública que permite comprender desigualdades sociales y de salud asociadas a la injusticia social (18-20).

En los estudios mencionados, algunas de las PIS de las mujeres en EPP en Colombia se muestran problemáticas (9-15); sin embargo, encontramos como vacío en la investigación la ausencia de visibilización de las desigualdades en las prácticas institucionales 
en salud, que podrían originar experiencias de procedimientos invasivos no consentidos en el EPP, de manera diferencial según la clase social $(8,21)$. De acuerdo con lo anterior, surge la pregunta objeto de la presente investigación, acerca de si existen desigualdades, según la clase social, en las prácticas institucionales que se realizan en las mujeres en EPP en los servicios de salud de Bogotá (Colombia).

\section{MATERIALES Y MÉTODOS}

Este proyecto se formula a partir de uno de los objetivos específicos de una investigación más amplia (22). En esta investigación se formularon otros dos objetivos específicos cuyos resultados ya fueron publicados $(23,24)$.

Diseño y población. Se realizó un estudio cualitativo, desde el paradigma de la hermenéutica crítica (25), que da cuenta de la reflexividad y subjetividad de la investigadora principal, que se identifica como mujer, médica y madre. El método es la etnografía crítica (26), que permite no solo entrevistar a los participantes de la investigación, sino también aproximarse a la perspectiva de otros actores, al contexto epidemiológico del EPP en Bogotá, y a las políticas del sistema de salud colombiano que dan significado a los resultados. El diseño metodológico fue flexible, coherente con el paradigma y método. Esto implica adaptar el proyecto a las necesidades del trabajo de campo y tener en cuenta las categorías y los referentes teóricos que emergen en la relación con los sujetos.

El trabajo de campo empezó en noviembre 2017 y finalizó en diciembre 2018. En esta fase se hizo presencia en el terreno, y se realizaron intercambios virtuales en las redes sociales a fin de crear sintonía con los participantes para generar un ambiente de confianza donde los sujetos pudieron expresar libremente lo que pensaban en el momento que ellos lo deseaban. La fase de análisis y redacción de la información inició en el trabajo de campo y finalizó en noviembre 2019.

Los criterios de inclusión fueron mujeres en primer trimestre de embarazo o más en la ciudad de Bogotá, que asistieron a instituciones públicas y privadas, pertenecientes a los regímenes subsidiado y contributivo del Sistema General de Seguridad Social en Salud (SGSS). Se excluyeron del estudio mujeres con enfermedad mental, discapacidad, menores de edad y quienes pudieran cambiar de residencia fuera de Bogotá.

Muestreo: teórico (27), según los conceptos de clase social de Breilh $(17,28)$, quien expone la clase social como una categoría analítica, en concordancia con el proceso de trabajo de la población y su relación con los medios de producción. En esta teoría se identifican los siguientes elementos diferenciadores entre las mujeres: ocupación, tipo de trabajo, actividad económica, empresa, contrato; grado, control y proceso de trabajo (vigila, realiza trabajo); posesión de medios de producción (propietario o no del lugar donde trabaja); fuente y forma de obtención de recursos. Lo anterior determina el régimen de salud en Colombia (29). En ese sentido, en la presente investigación participaron tres mujeres con trabajo informal que pertenecen al régimen subsidiado, tres mujeres asalariadas que pertenecen al régimen contributivo y tres mujeres con capacidad de ahorro que dentro del régimen contributivo pueden pagar un seguro privado o prepagada (tabla 1). Los conceptos de clase social, régimen de salud e instituciones públicas y privadas están relacionados en el marco referencial elegido.

Procedimiento. Según el presupuesto y el tiempo programado para realizar el trabajo de campo, se acompañaron 9 mujeres (tabla 1). Dada la conceptualización de clase social se hubiera podido invitar a más mujeres a la investigación, por eso no se cumplió con el criterio de saturación de la información (27). Las mujeres fueron contactadas a través de redes sociales y el servicio de control prenatal del sector público, donde tres mujeres rechazaron participar pues no requerían el acompañamiento propuesto.

Se invitó a participar al personal de salud que estaba en contacto con las mujeres. La mayoría rechazó participar en la investigación sin aportar razón alguna. Por tanto, se cambió la estrategia y fue 


\begin{tabular}{|c|c|c|c|c|c|c|c|c|c|c|}
\hline Mujer & $\begin{array}{l}\text { Régimen } \\
\text { salud }\end{array}$ & $\begin{array}{l}\text { Edad } \\
\text { (años) }\end{array}$ & $\begin{array}{l}\text { Semanas } \\
\text { gestación } \\
\text { inicio } \\
\text { estudio }\end{array}$ & Ocupación & $\begin{array}{c}\text { Nivel } \\
\text { educativo }\end{array}$ & $\begin{array}{c}\text { Estado } \\
\text { civil }\end{array}$ & $\mathrm{ESE}^{\mathrm{a}}$ & $\begin{array}{l}\text { Fuente } \\
\text { ingresos }\end{array}$ & $\begin{array}{l}\text { Localidad } \\
\text { vivienda }\end{array}$ & $\begin{array}{l}\text { Localidad } \\
\text { servicios } \\
\text { salud }\end{array}$ \\
\hline $\mathrm{Gp}$ & Prepagada & 38 & 27 & $\begin{array}{c}\text { Empresaria } \\
\text { servicios } \\
\text { privados } \\
\text { medicina } \\
\text { estética }\end{array}$ & $\begin{array}{c}\text { Profesional } \\
\text { Medicina } \\
\text { Posgrado }\end{array}$ & Casada & 5 & $\begin{array}{c}\text { Trabajo } \\
\text { (de ella, } \\
\text { pareja) } \\
\text { y } \\
\text { propiedades }\end{array}$ & Usaquén & Usaquén \\
\hline Ap & $\begin{array}{c}\text { Plan } \\
\text { comple- } \\
\text { mentario } \\
\mathrm{C}^{\mathrm{b}}\end{array}$ & 32 & 8 & $\begin{array}{c}\text { Ama de } \\
\text { casa }\end{array}$ & $\begin{array}{c}\text { Profesional } \\
\text { Ingeniería }\end{array}$ & Casada & 3 & $\begin{array}{c}\text { Trabajo } \\
\text { pareja y } \\
\text { propiedades }^{c}\end{array}$ & $\begin{array}{c}\text { Cercanía } \\
\text { Suba }\end{array}$ & Chapinero \\
\hline $\mathrm{Lp}$ & $\begin{array}{c}\text { Plan } \\
\text { comple- } \\
\text { mentario } \\
\text { S }\end{array}$ & 34 & 32 & $\begin{array}{c}\text { Trabajo } \\
\text { informal } \\
\text { investigadora }\end{array}$ & $\begin{array}{c}\text { Profesional } \\
\text { Antropología } \\
\text { Posgrado }\end{array}$ & $\begin{array}{l}\text { Unión } \\
\text { marital } \\
\text { de } \\
\text { hecho }\end{array}$ & 3 & $\begin{array}{l}\text { Trabajo } \\
\text { de ella, } \\
\text { pareja, } \\
\text { padre }\end{array}$ & Engativá & $\begin{array}{c}\text { Chapinero, } \\
\text { Usaquén }\end{array}$ \\
\hline $\mathrm{Kc}$ & $\begin{array}{c}\text { Contributivo } \\
\text { S }\end{array}$ & 27 & 28 & Asalariada & $\begin{array}{l}\text { Profesional } \\
\text { Ingeniería }\end{array}$ & Casada & 3 & $\begin{array}{l}\text { Trabajo } \\
\text { de ella, } \\
\text { pareja }\end{array}$ & Kennedy & $\begin{array}{c}\text { Kennedy, } \\
\text { Teusaquillo }\end{array}$ \\
\hline Ac & $\begin{array}{c}\text { Contributivo } \\
\text { N }\end{array}$ & 23 & 16 & Asalariada & $\begin{array}{l}\text { Técnica en } \\
\text { gestión de } \\
\text { archivo }\end{array}$ & Casada & 2 & $\begin{array}{l}\text { Trabajo } \\
\text { de ella, } \\
\text { pareja }\end{array}$ & Bosa $^{f}$ & $\begin{array}{c}\text { Bosa }^{\mathrm{f}} \text {, } \\
\text { Chapinero } \\
\text { Puente } \\
\text { Aranda }\end{array}$ \\
\hline Lc & $\begin{array}{c}\text { Contributivo } \\
\text { C }\end{array}$ & 18 & 20 & $\begin{array}{c}\text { Ama de } \\
\text { casa }\end{array}$ & Bachiller & Soltera & 2 & $\begin{array}{l}\text { Trabajo, } \\
\text { padres, } \\
\text { hermanos }\end{array}$ & $\operatorname{Bosa}^{\mathrm{f}}$ & $\begin{array}{l}\text { Kennedy } \\
\text { Usaquén } \\
\text { Puente } \\
\text { Aranda }\end{array}$ \\
\hline Ss & $\begin{array}{c}\text { Subsidiado } \\
\text { ES }^{\mathrm{d}}\end{array}$ & 19 & 25 & $\begin{array}{c}\text { Ama de } \\
\text { casa }\end{array}$ & $\begin{array}{c}\text { Séptimo } \\
\text { bachillerato }\end{array}$ & $\begin{array}{l}\text { Unión } \\
\text { marital } \\
\text { de } \\
\text { hecho }\end{array}$ & 1 & $\begin{array}{c}\text { Trabajo } \\
\text { pareja, suegra }\end{array}$ & $\begin{array}{l}\text { Ciudad } \\
\text { Bolívar }^{\mathrm{f}}\end{array}$ & $\begin{array}{c}\text { Ciudad } \\
\text { Bolívar }^{\mathrm{f}} \\
\text { Tunjuelito }^{\mathrm{f}}\end{array}$ \\
\hline Gs & $\begin{array}{c}\text { Subsidiado } \\
\text { ES }\end{array}$ & 36 & 20 & $\begin{array}{c}\text { Trabajo } \\
\text { informal varios }\end{array}$ & $\begin{array}{c}\text { Octavo } \\
\text { bachillerato }\end{array}$ & Soltera & 1 & $\begin{array}{l}\text { Trabajo } \\
\text { de ella }\end{array}$ & $\operatorname{Bosa}^{f}$ & $\mathrm{Bosa}^{\mathrm{f}}$ \\
\hline Vs & $\begin{array}{c}\text { Subsidiado } \\
\text { FF }^{\mathrm{e}}\end{array}$ & 27 & 38 & Ama de casa & Bachiller & Soltera & 1 & $\begin{array}{l}\text { Trabajo } \\
\text { padres }\end{array}$ & $\begin{array}{l}\text { Ciudad } \\
\text { Bolívar }^{f}\end{array}$ & $\begin{array}{l}\text { Ciudad } \\
\text { Bolívar }^{\mathrm{f}}\end{array}$ \\
\hline
\end{tabular}

a. Estratos socioeconómicos. En Colombia son 6, donde el 1 es el más bajo y el 6 el más alto. Esta estratificación se realiza de acuerdo con el lugar de la vivienda. B. A pesar de que dos mujeres tienen planes complementarios, las empresas que prestan los servicios son diferentes y, por tanto, las clínicas de atención son diferentes. Lo anterior también sucede en el régimen contributivo y subsidiado. Por esta razón, se coloca la inicial para visibilizar las empresas que son diferentes. En Colombia la mayoría de los usuarios del régimen subsidiado son atendidos en instituciones públicas, el resto de usuarios son atendidos en instituciones privadas. c. Familias que tienen capacidad de ahorro y reciben ingresos de otras fuentes diferentes al trabajo (arriendos, alquiler de equipos). d. EPS subsidiada. e. Fondo Financiero. f. Localidades del sur de Bogotá vulnerables, con peores indicadores de salud materno-fetal, contaminación ambiental, déficit de transporte público, inseguridad, déficit de servicios de salud, traslados prolongados entre el domicilio y los servicios de salud, servicios de salud públicos involucrados en corrupción, hacinamiento. 
contactado personal de salud, con experiencia en atención materna, a través de redes sociales, así no estuviera en contacto con las mujeres participantes. Esta aproximación permitió la participación de 8 profesionales de la salud (tabla 2), dos de los cuales eran conocidos de la investigadora principal antes de la investigación.

Previo al trabajo de campo se programó hacer una entrevista con las mujeres por cada trimestre de embarazo, una entrevista posparto y otra entrevista después de finalizada la licencia de maternidad. Estas se desarrollaron a profundidad de manera longitudinal en el proceso de EPP durante 13 meses. Se realizaron 30 entrevistas a las mujeres y una a cada trabajador de la salud para un total de 38 entrevistas.
En el trabajo de campo, el tiempo planificado inicialmente para realizar las entrevistas cambió según las dificultades de las mujeres. Por ejemplo, una de ellas tuvo una pérdida gestacional al cuarto mes de embarazo. Con esta participante solo se realizaron dos entrevistas posaborto en el momento que lo deseó la mujer. A pesar de lo anterior, el acompañamiento de la mujer continuó, sin importar que las PIS pudieran ser diferentes a las previstas. En este caso, el paradigma elegido permite aproximarse a categorías nuevas que emergen en el campo y desde una postura ética se priorizan las necesidades de los participantes. Estos aspectos relacionados hacen parte de la etnografía (22).

Las entrevistas fueron realizadas por la investigadora principal, de manera no estructurada, con pre-

\begin{tabular}{|c|c|c|c|c|}
\hline Tipo & $\begin{array}{l}\text { Lugar de } \\
\text { trabajo }\end{array}$ & Sexo & Edad & $\begin{array}{c}\text { Experiencia laboral } \\
\text { en maternidad (años) }\end{array}$ \\
\hline $\begin{array}{l}\text { Obstetra, atención de partos, } \\
\text { consulta externa, preparación } \\
\text { parto }\end{array}$ & Prepagada & $\mathrm{F}$ & 48 & 18 \\
\hline Asesora de lactancia materna & $\begin{array}{l}\text { Prepagada y } \\
\text { contributivo }\end{array}$ & $\mathrm{F}$ & 41 & 21 \\
\hline Enfermera, consulta externa & $\begin{array}{l}\text { Prepagada y } \\
\text { contributivo }\end{array}$ & $\mathrm{F}$ & 28 & 4 \\
\hline $\begin{array}{l}\text { Médica, atención de partos, } \\
\text { consulta externa }\end{array}$ & $\begin{array}{l}\text { Contributivo } \\
\text { y subsidiado }\end{array}$ & $\mathrm{F}$ & 40 & 5 \\
\hline Obstetra, consulta externa & Subsidiado & M & 54 & 25 \\
\hline $\begin{array}{l}\text { Obstetra, atención de partos, } \\
\text { consulta externa }\end{array}$ & Subsidiado & $\mathrm{F}$ & 32 & 8 \\
\hline $\begin{array}{l}\text { Enfermera, consulta externa } \\
\text { y preparación embarazo, } \\
\text { parto y posparto }\end{array}$ & Subsidiado & $\mathrm{F}$ & 46 & 15 \\
\hline $\begin{array}{l}\text { Fisioterapeuta, atención de partos, } \\
\text { preparación embarazo, parto y } \\
\text { posparto }\end{array}$ & $\begin{array}{l}\text { Contributivo } \\
\text { y prepagada }\end{array}$ & $\mathrm{F}$ & 33 & 5 \\
\hline
\end{tabular}


guntas abiertas (30). Se utilizó una guía que incluyó temas relacionados con la clase social $(17,28)$ y los significados de las prácticas institucionales de salud $(1,31,32)$, adaptada según la situación particular de cada mujer. Los encuentros se programaron según la disponibilidad de las participantes, en lugares elegidos por ellas, en organizaciones sociales, en el domicilio cuando las mujeres estaban solas, y en restaurantes poco frecuentados. La duración fue de una hora en promedio y mantuvieron un carácter confidencial.

La observación participante $(\mathrm{OP})(26,33)$ fue realizada por la investigadora principal en los servicios de salud donde asistieron a las mujeres. Se ingresó a varias instituciones, tanto públicas como privadas, según los diferentes seguros de salud (tabla 1). La mayoría de las mujeres transitaron por distintos niveles de atención y de complejidad; en general, el control prenatal se realizó en el primer nivel y la atención del parto en segundo y tercer nivel. Otras características de las instituciones y los tránsitos de las mujeres se describen en la investigación etnográfica original (22).

Se efectuaron 62 acompañamientos a maternas en las diferentes instituciones de salud (tabla 1). Lo observado se registró en el diario de campo donde se tomaron pequeñas notas a diario y se intentó que no se bloqueara la interacción con los sujetos. La redacción completa se realizó cuando no se estaba en el terreno. En el diario de campo quedó registrada la reflexividad de la investigadora principal y las transformaciones que presentaron los sujetos que participaron. Lo anterior se organizó en itinerarios de acompañamiento (uno por cada mujer participante), en forma de relato etnográfico y se recopiló información relacionada con el contexto (22).

Estrategias de análisis de la información: en los itinerarios de acompañamiento se identificaron aspectos en común de las participantes y los que las diferenciaban. Esta información se organizó en el proceso de EPP, lo que permitió ver recurrencias de aspectos teóricos a través del tiempo por cada una de las mujeres (33). Lo anterior se transcribió en un formato
Excel y fue un insumo importante para el análisis de las entrevistas pues había aspectos en ellas que parecían no recurrentes, pero que al triangularlos con los itinerarios de acompañamiento adquirían importancia teórica. Las entrevistas fueron grabadas por la investigadora principal y transcritas por dos transcriptoras de la Universidad CES de Medellín. Las transcripciones de las entrevistas y el itinerario de acompañamiento fueron entregados a los participantes para retroalimentación.

El análisis se realizó en Atlas ti versión 7, donde se le asignó un código a los párrafos o frases, lo cual permitió clasificar la información. Se buscó desagregar datos, para volverlos a unir de manera diferente en forma de categorías. Esto busca construir conceptos relacionados con la teoría (análisis de contenido) y agrupar datos que tengan significados similares, con el fin de construir conceptos que den sentido a los resultados (34). Se identificaron 179 códigos derivados de los datos, organizados en 11 categorías. En el presente documento se publican 2 categorías en los resultados. Estas dos categorías se denominan: el mercado regula la salud, y vigilancia y control en los servicios de salud. Algunas de las otras categorías han sido publicadas previamente $(23,24)$. El proceso de codificación se realizó con el grupo de investigación y una trabajadora social.

Se triangularon $(27,35)$ los resultados teniendo en cuenta las técnicas metodológicas y el proceso de socialización. Este se realizó con pares investigadores de la Universidad CES y expertos en el tema, ajenos al proceso, lo que permitió incluir perspectivas diferentes e interdisciplinarias. Igualmente, la socialización fue progresiva con los participantes para validar la información y proponer estrategias que emerjan de ellos mismos.

Criterios de rigor metodológico en investigación cualitativa $(35,36)$ : en la confiabilidad se diferenciaron los discursos de los actores de los análisis de la investigadora principal. Hubo tiempo suficiente para construir una relación de confianza con las personas. Los resultados fueron socializados de forma progresiva con las y los participantes, expertos en 
el tema, incluyendo perspectivas interdisciplinarias. En la credibilidad se evaluó el efecto de la investigadora principal, aspectos que están descritos en la etnografía principal (22). El marco referencial y la recolección de la información fueron realizados en diferentes momentos del proceso investigativo. Se analizaron resultados desde diferentes teorías $(1,8,17,18,21,31,32,37,38)$ y fueron incluidas las perspectivas de otros sujetos no participantes. El relato etnográfico contextualizado se construyó con información descriptiva y detallada (22). En la auditabilidad, los registros y los audios estuvieron a disposición de evaluadores externos ajenos al proceso para verificar resultados. Se desarrolló un informe de memoria metodológica que hizo explícitos los ajustes al proyecto realizados según las necesidades del trabajo de campo. En la consistencia se triangularon datos teniendo en cuenta lo observado en el diario de campo, el discurso de los actores, la verificación resultados por evaluadores externos, y las cifras estadísticas del contexto. Los datos en relación con los discursos de los participantes obtenidos de las entrevistas (tabla 3, 4) se confrontaron en el proceso de triangulación, con la observación participante realizada por la investigadora principal en el trabajo de campo, y los datos obtenidos del contexto (22). En la transferibilidad se construyeron el contexto y los itinerarios de acompañamiento con información descriptiva y detallada (22) como insumo para comparar con otros contextos urbanos latinoamericanos con sistemas de salud similares.

Aspectos éticos. Se contó con aprobación del comité de ética de la Universidad CES (Acta 99/2016) y de la Secretaría de Salud de Bogotá (Acta N00 41000/2017). Según el código de ética médica colombiano, en el ámbito asistencial se respetaron las decisiones clínicas tomadas por el personal de salud, pues la atención dada por los trabajadores de la salud excluyó la posible atención médica requerida de la investigadora principal. En el consentimiento informado se aclaró quién era la investigadora y sus intereses siendo mujer, médica y madre.

\section{RESULTADOS}

Participaron mujeres de estratos 1 al 5, con edades desde los 18 a los 38 años, nivel educativo séptimo de bachillerato hasta posgrado, ocupación (ama de casa, asalariada, empresaria, trabajo informal), y régimen de salud (subsidiado, contributivo básico, contributivo prepagada y planes complementarios). Los servicios de salud estaban ubicados en diferentes localidades de Bogotá que contrastan por las desigualdades sociales y de salud (39) (tabla 1). También participaron 8 profesionales de la salud (tabla 2) que trabajan en cada uno de los regímenes de salud, en consulta de control prenatal, y atención del parto y posparto.

Como resultado del análisis se construyeron dos categorías emergentes en el trabajo de campo (figuras 1 y 2) en relación con las PIS. Los datos fueron organizados en códigos (tabla 3 y 4) que representan un concepto que, al relacionarse entre sí, le da sentido a la categoría.

\section{Categoría: el mercado regula la salud}

Las PIS están inmersas en el contexto del sistema de salud colombiano, el cual está regulado por políticas en salud (figura 1). En la búsqueda de datos de contexto en relación con lo anterior se encontró que la Ley 100 de 1993 estuvo enmarcada bajo políticas neoliberales de tipo económico que nacieron en los años setenta a nivel mundial para disminuir el gasto público en salud dada la crisis del capitalismo global. Estas políticas fueron importadas a Colombia, lo que provocó que el mercado reemplazara al Estado en la regulación económica, y la justicia social quedara relegada a los procesos de oferta y demanda en los servicios de salud. Adicionalmente, el Estado delega la prestación del servicio de salud público a seguros privados (Entidades Promotoras de Salud - EPS) con ánimo de lucro, lo cual afecta el derecho a la salud de las personas y los derechos laborales del personal de salud (40-44).

En relación con el discurso de los participantes, que sustentan la presente categoría, estos dan 
Figura 1.

El mercado que regula la salud en Colombia, 2018

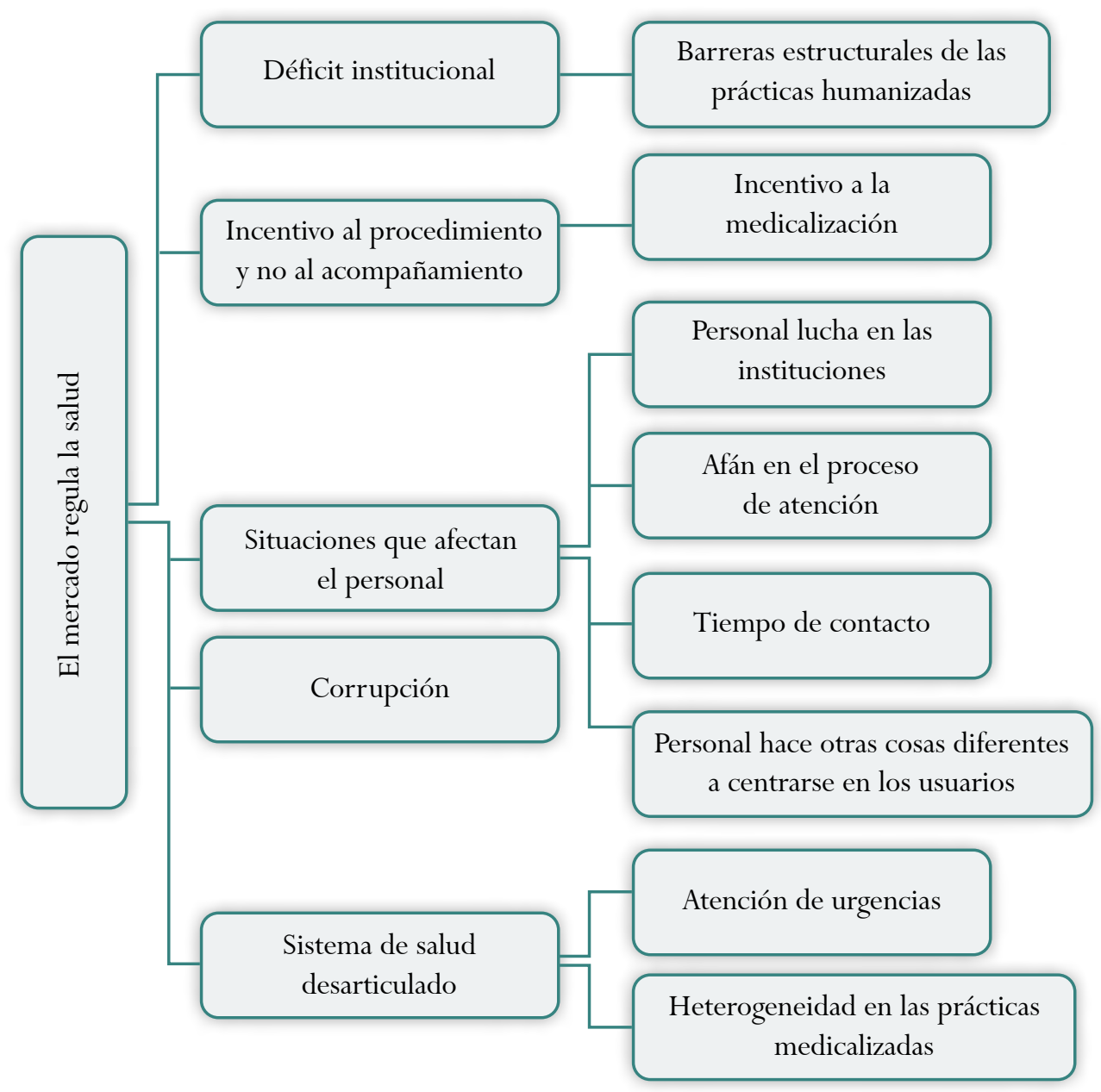

cuenta de que las PIS se reproducen en la forma como funciona el sistema de salud colombiano. Con respecto a los códigos "Incentivo económico al procedimiento" y "Corrupción" (tabla 3), en la presente investigación se intenta visibilizar que las PIS, como la inducción medicalizada del parto y la cesárea, en condiciones fisiológicas, se presentan en situaciones no recomendadas por la evidencia científica (3), y se relacionan con aspectos estructurales de tipo económico, todo lo cual es relevante en la conceptualización de la violencia obstétrica (6)

Estos aspectos se confrontaron con los datos de contexto que mostraron que para 2016, el porcentaje de partos por cesárea en Colombia fue de 45,8 \% y para Bogotá fue de $43 \%$. En algunos departamentos colombianos, como el Atlántico, la tasa es de $68 \%$ (45). Esta tasa de cesáreas ha aumentado a través del tiempo y es una de las más altas a nivel mundial.

En Colombia, los determinantes más relevantes asociados a la tasa de cesáreas están relacionados con el prestador de servicios. Entre estos determinantes se encuentran con mayor tasa de cesáreas las siguientes variables: el sector privado, los incentivos financieros del prestador (pago del evento), y el nivel de especialización de la IPS que tiene servicio de obstetricia (46). Según la Organización Mundial de la Salud (OMS), cuando las frecuencias de cesáreas son superiores al 10-15\%, no se da un efecto signi- 
Figura 2.

La vigilancia y el control en los servicios de salud

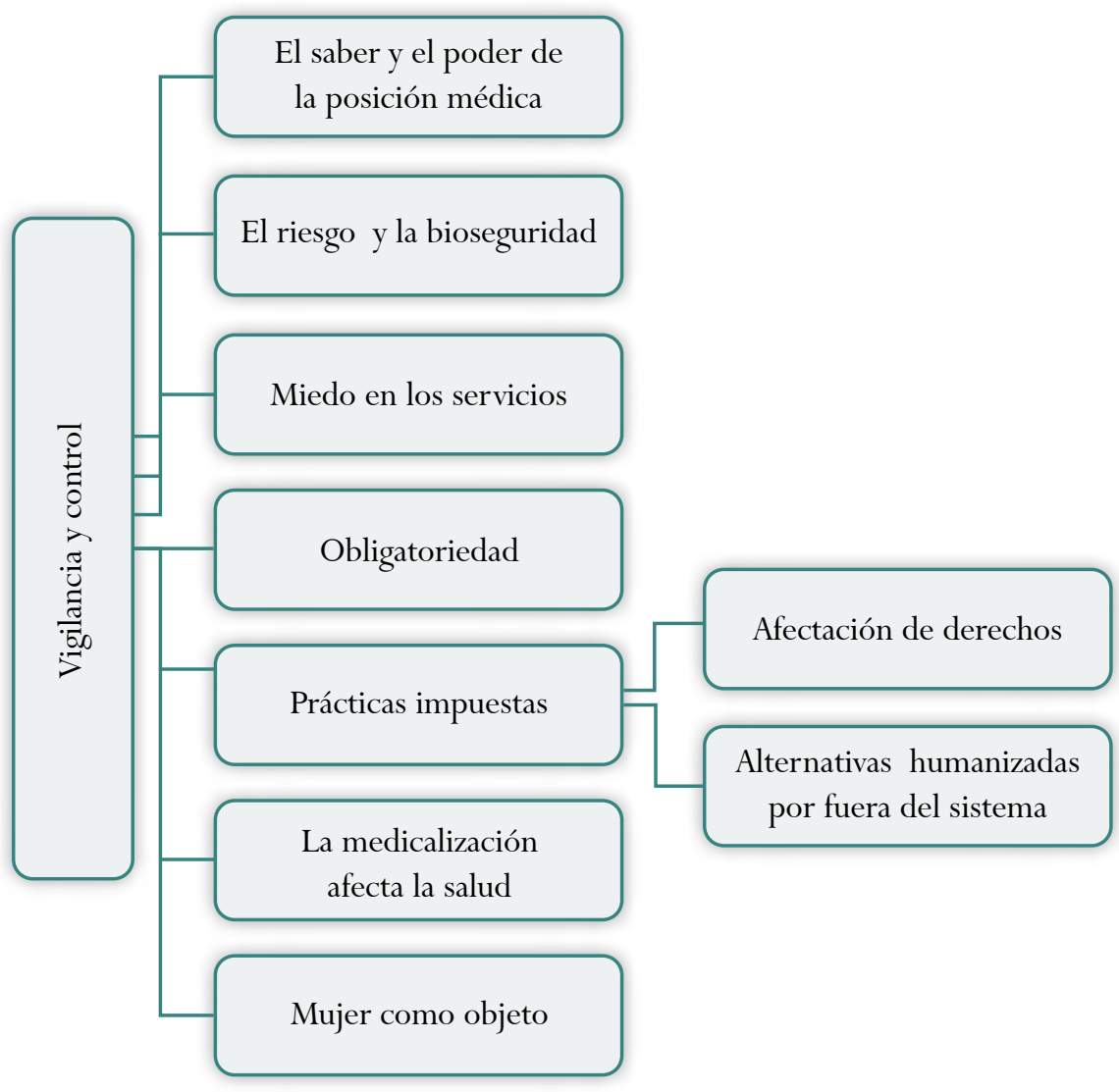

ficativo en la disminución de las tasas de mortalidad materna o neonatal; esto afecta la salud del binomio madre-hijo, pues la cesárea programada sin indicación médica tiene efectos secundarios (47). No obstante, existen otras opiniones con relación a esta tasa de cesáreas, por ejemplo, en varios países miembros de la OMS se ha hecho hincapié en que un porcentaje por debajo del $19 \%$ en la tasa de cesáreas puede disminuir la mortalidad materna o neonatal (48). Por ello, agremiaciones de obstetras y perinatólogos colombianos han realizado recomendaciones, basadas en evidencia, para disminuir la tasa de cesáreas, teniendo en cuenta la seguridad en la atención (49). Estas recomendaciones están enfocadas en el comportamiento individual de los actores involucrados, pero sin visibilizar aspectos estructurales relacionados con los temas expues- tos en la tabla 3, referentes al funcionamiento del sistema de salud colombiano.

Referente al código "Déficit institucional" (tabla 3), en relación con el número de camas, ambulancias y cierre de servicios de maternidad, se confrontó esta información con los datos encontrados en el contexto que mostraron que en Colombia la construcción hospitalaria viene en descenso desde 2014 y aumentan las construcciones hospitalarias que están paralizadas y no finalizadas (50). Para 2018, por cada 10.000 habitantes había 7,3 camas y 0,51 ambulancias básicas y medicalizadas. Para 2017, en Bogotá había 0,26 camas por cada 10.000 habitantes y 0,00 ambulancias por cada 10.000 habitantes (51). Lo anterior muestra un déficit cuando se comparan estos indicadores con otros países. Para 2011 había 21 camas por 10.000 habitantes 


\begin{tabular}{|c|c|c|}
\hline Código & Definición conceptual & Citas \\
\hline $\begin{array}{l}\text { Déficit } \\
\text { institucional }\end{array}$ & $\begin{array}{l}\text { Falta de insumos, infraestructura y talento humano en } \\
\text { las instituciones de salud. Este aspecto está relacio- } \\
\text { nado con las barreras estructurales para el desarrollo } \\
\text { de las prácticas humanizadas. Por ejemplo, la falta de } \\
\text { anestesia epidural, privacidad en la sala de partos, es- } \\
\text { pacio para acondicionar salas de partos que permitan } \\
\text { el movimiento en el trabajo de parto, personal que } \\
\text { acompañe a las maternas durante el trabajo de parto, } \\
\text { camas que permitan tener a una materna el tiempo } \\
\text { suficiente para el desarrollo de un parto natural, } \\
\text { ambulancias para remitir los pacientes de un primer } \\
\text { nivel al siguiente nivel de atención. }\end{array}$ & $\begin{array}{l}\text { "Disminuyeron en el hospital público el número } \\
\text { de profesionales y las camas, en este momento } \\
\text { solamente hay } 12 \text { camas para todo lo que lle- } \\
\text { gue, hay } 6 \text { camillas de observación para lo que } \\
\text { llegue, entonces se mete en el mismo espacio a } \\
\text { pediátricos y a gestantes. En el mismo espacio, } \\
\text { todo queda igual, todo quedó en la misma área y } \\
\text { el espacio que estaba destinado para obstetricia } \\
\text { que era aparte y el de pediatría que era aparte, } \\
\text { eso está clausurado, ahí no se hace nada" (Médi- } \\
\text { ca general, régimen subsidiado y contributivo). }\end{array}$ \\
\hline $\begin{array}{l}\text { Incentivo } \\
\text { económico } \\
\text { al procedi- } \\
\text { miento }\end{array}$ & $\begin{array}{l}\text { Estrategia del sistema de salud que valora econó- } \\
\text { micamente los procedimientos medicalizados y la } \\
\text { tecnología en salud, pero esto mismo no sucede con } \\
\text { los aspectos relacionados con la humanización como } \\
\text { el acompañamiento que se les hace a las maternas } \\
\text { en el trabajo de parto y las valoraciones basadas en } \\
\text { la clínica. }\end{array}$ & $\begin{array}{l}\text { "Fueron dos días y medio acompañando el } \\
\text { trabajo de parto y recibí mi tarifa de siempre, } \\
\text { como si hubiera estado como } 1 \text { hora. Enton- } \\
\text { ces parte del planteamiento es que volvamos a } \\
\text { institucionalizar la obstetricia en el sector pri- } \\
\text { vado, porque finalmente ahí sí se solucionarían } \\
\text { algunos de los problemas en términos de que } \\
\text { no estaríamos con afanes viviendo inducciones } \\
\text { fallidas como de tres horas y como no tengo } \\
\text { tiempo de acompañarte más ni tampoco me } \\
\text { lo pagan, pues hagamos cesárea, daríamos más } \\
\text { como espera a los tiempos naturales que tiene } \\
\text { cada mujer para parir" (Obstetra, medicina } \\
\text { prepagada). }\end{array}$ \\
\hline $\begin{array}{l}\text { Situación } \\
\text { que afecta } \\
\text { al personal } \\
\text { de salud }\end{array}$ & $\begin{array}{l}\text { Condiciones en que el personal desarrolla su tra- } \\
\text { bajo, donde hay déficit institucional y no se valora } \\
\text { económicamente el proceso de acompañamiento } \\
\text { de las maternas. Esto provoca situaciones de so- } \\
\text { brecarga laboral y agotamiento que es considerado } \\
\text { como violencia contra el personal. Adicionalmente, } \\
\text { el personal debe adaptarse a las demandas del mer- } \\
\text { cado que impone tiempos de atención reducidos y } \\
\text { rentabilidad relacionados con el afán en el proceso } \\
\text { de atención y la necesidad de inducir médicamente } \\
\text { el parto. La manera como funciona el sistema genera } \\
\text { cargas administrativas que alejan al profesional de } \\
\text { la atención de las mujeres. Para el personal que ha } \\
\text { sido capacitado en el concepto de parto humanizado } \\
\text { aplicar esta perspectiva genera luchas y resistencias } \\
\text { en los servicios de salud. }\end{array}$ & $\begin{array}{l}\text { "Me quedo colgada en el tiempo y me puedo } \\
\text { retrasar una hora y obviamente son quejas y tam- } \\
\text { bién me lo auditan. Me hacen plan de mejora } \\
\text { entonces entro en vigilancia en un tiempo X y } \\
\text { si no muestro resultados pues me terminan el } \\
\text { contrato" (Médica general, régimen subsidiado } \\
\text { y contributivo). }\end{array}$ \\
\hline
\end{tabular}




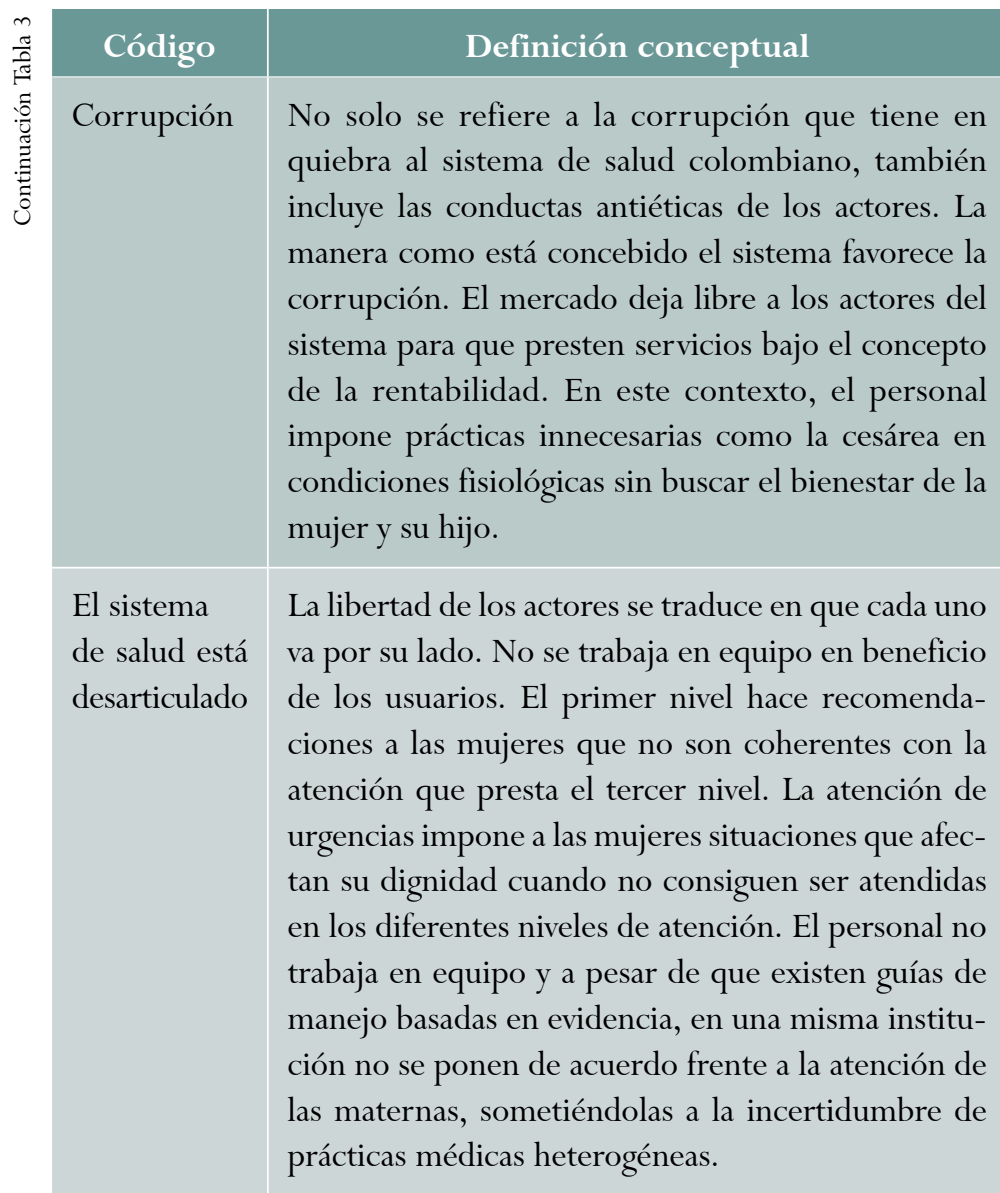

Citas

"La doctora dijo: 'para acelerar el parto, pues lo tendría en mi turno, pues yo la dejo para parto normal. En cambio, mi compañero no, si él llega mañana y usted no ha tenido el bebé la manda de una vez a cesárea"” (Mujer bachiller, ama de casa, beneficiaria del régimen contributivo).

"Hay una soledad para las prácticas de la humanización. El sistema ha fraccionado los equipos, no trabajamos en equipo, pues como que el sistema tiene tan alto nivel de exigencia que fracciona y cada uno trabaja el pedacito que le corresponde... Por ejemplo, una bebida hidratante es un detalle tan sencillo, que es posible, y que bueno yo lo he vivido en algunas de las instituciones en las que trabajo, en otras es más luchado. La enfermera jefe me dice 'doctora vaya y pídale permiso al anestesiólogo si la deja darle agua'" (Obstetra, medicina prepagada). prácticas médicas heterogéneas.

en Chile y 82 en Alemania (52). En Colombia hay insuficiencia de servicios especializados, se cierran servicios de pediatría y obstetricia porque no son rentables y la oferta se concentra en servicios de alto costo $(53,54)$.

En los datos de la OP se señaló que este déficit de camas y ambulancias es significativo porque la programación de un parto humanizado (3) requiere tiempo y espacio, acordes con el proceso natural del trabajo de parto, donde se garantice la seguridad del binomio madre-hijo en caso de necesitar remisión a otro nivel de atención (22).

Articulado al "déficit institucional" (tabla 3), en los datos de contexto son visibles las desigualdades entre las instituciones públicas y privadas (55), lo cual afecta los derechos de las mujeres del régimen subsidiado. Al respecto, en Bogotá el 99,3\% de IPS (clínicas y hospitales) son privadas. En 2016, había 18 IPS públicas menos con respecto al 2015. Para el caso de ginecobstetricia había 611 servicios habilitados en el sector privado y 34 en el público. Para pediatría había 603 servicios privados y 27 públicos (55).

En los datos de la OP se apreció que las problemáticas relacionadas con el "déficit institucional" y los tiempos reducidos de atención en "Situación que afecta el personal de salud" (tabla 3), se acentuaron en las mujeres de régimen subsidiado y algunas de régimen contributivo. Esto vulnera en mayor medida a las mujeres de una clase social menos aventajada (22).

Lo anterior se confrontó con los datos de contexto que dan cuenta de la difícil situación de los hospitales públicos colombianos, los cuales no reciben el dinero del Estado sino de empresas privadas, a través de cuentas de cobro, en un contexto donde se presta un servicio menos competitivo de salud integral, educación y gratuidad $(43,44)$.

Los recursos son retenidos por las EPS a través de la auditoría médica, malversación de fondos y 
competencia desleal $(43,44)$. Lo anterior provoca el cierre de instituciones de salud para las personas más necesitadas del país y el despido masivo y violento del personal, como sucedió con los hospitales públicos más representativos de Bogotá (Materno Infantil y San Juan de Dios), a partir de la reforma neoliberal. En los hospitales públicos que continúan vigentes en la actualidad se evidencia la flexibilización del trabajo del personal, su explotación, y una visión del usuario pobre como objeto de gestión económica $(43,44)$.

Estos aspectos influyen de manera importante en la salud pública, pues la desfinanciación de las instituciones de salud afecta la calidad en la prestación de servicios de salud, no solo por la falta de insumos, sino por la situación del personal de salud $(22,56)$. Lo anterior no es evidenciado a profundidad en los documentos producidos por los entes estatales $(51,55,57)$, que son fundamentales para ejecutar la Política de Atención Integral en Salud en Colombia (58).

Los datos de la OP permitieron generar diálogos con los obstetras participantes (tabla 2). Ellos manifestaron no estar de acuerdo con la normatividad que busca penalizar la violencia obstétrica en Colombia. Sin embargo, no pertenecen a ningún colectivo político que busque la transformación del sistema de salud colombiano. Al respecto, los datos del contexto mostraron que un gremio de obstetras a nivel nacional manifestaron estar en desacuerdo con el proyecto de ley que penaliza la violencia obstétrica porque la responsabilidad recae sobre los individuos y no se enfoca en otras causas más estructurales (59).

\section{Categoría: la vigilancia y el control en los servicios de salud}

Vigilar y controlar clínicamente a las mujeres es una herramienta en el proceso de atención de las maternas que busca disminuir la morbimortalidad materno-infantil (figura 2). Los datos, en relación con los discursos de los participantes, que sustentan esta categoría se presentan en la tabla 4.
Los datos de la OP mostraron que los derechos del parto humanizado solo son asequibles para las mujeres con mayor poder adquisitivo (22). Por ejemplo, el derecho a disminuir la percepción del dolor, ya sea con la analgesia epidural u otros métodos naturales, derecho a la privacidad en el trabajo de parto, derecho a tener un acompañante en el trabajo de parto, derecho a elegir el personal que atiende el parto, y oportunidad de pagar una doula (acompañante en el EPP que promueve en condiciones fisiológicas el parto natural no inducido y el trabajo de parto en movimiento en sintonía con las necesidades de la mujer) (60).

Para el caso de la presente investigación, solo una mujer de medicina prepagada pudo sufragar la doula que trabajó en equipo con un obstetra de una clínica privada para garantizar un proceso humanizado y sin complicaciones a nivel institucional (tabla 4, código "Alternativas humanizadas por fuera del sistema”, y datos reportados en la etnografía (22)).

En respuesta a la pregunta de investigación, los datos de OP mostraron que las desigualdades según clase social para las PIS (tabla 4) son: prácticas medicalizadas impuestas, falta de derechos en relación con prácticas humanizadas y obligatoriedad en los servicios. En estos aspectos se afecta en mayor medida a las mujeres de una clase social menos aventajada (22).

\section{DISCUSIÓN}

Teniendo en cuenta el paradigma elegido (25) es necesario dar significado a los resultados a partir de la teoría y discutir el porqué de las problemáticas planteadas. Adicional a los aspectos teóricos publicados previamente $(8,21)$, son relevantes los referentes teóricos que emergen con los datos. Al respecto, Das (37) explica que las estructuras políticas nacionales e internacionales generan violencia estructural en la población. Las organizaciones internacionales imponen sus intereses en salud pública sobre las necesidades de las personas en el contexto local de los países en vías de desarrollo. La salud y la vigilancia se conceptualizan como "un bien 


\begin{tabular}{|c|c|c|}
\hline Código & Definición conceptual & Citas \\
\hline $\begin{array}{l}\text { Saber-Poder } \\
\text { de la posición } \\
\text { médica }\end{array}$ & $\begin{array}{l}\text { Los saberes de los galenos sobre el } \\
\text { cuerpo de las mujeres son considerados } \\
\text { un saber experto y autorizado que no } \\
\text { se cuestiona ni se pone en duda. En ese } \\
\text { sentido, las mujeres obedecen la auto- } \\
\text { ridad médica porque ellas no tienen el } \\
\text { conocimiento ni el reconocimiento que } \\
\text { los médicos tienen. }\end{array}$ & $\begin{array}{l}\text { "Si los médicos están diciendo que no es posible de } \\
\text { pronto la equivocada soy yo porque es que todo el } \\
\text { mundo lo dice y son personas que estudian para eso } \\
\text { o sea, como no creerles si están con especializaciones } \\
\text { precisamente y son especialistas en el tema entonces. } \\
\text { Que te digan que no, que está muy grande, pues ob- } \\
\text { viamente ya tú empiezas a dudar de que no es posible } \\
\text { el parto natural y no voy a insistir" (Mujer profesional, } \\
\text { ama de casa, plan complementario). }\end{array}$ \\
\hline $\begin{array}{l}\text { Riesgo y } \\
\text { bioseguridad }\end{array}$ & $\begin{array}{l}\text { Aspectos que justifican las prácticas me- } \\
\text { dicalizadas. Se visibilizan como verdades } \\
\text { absolutas, no se cuestionan y se impo- } \\
\text { nen para disminuir morbimortalidad } \\
\text { materno-infantil. }\end{array}$ & $\begin{array}{l}\text { "En una clínica que me dicen que por bioseguridad } \\
\text { del paciente no es permitida la movilidad de una } \\
\text { mujer en trabajo de parto a partir de la fase activa, } \\
\text { o sea de } 5 \text { centímetros de dilatación hacia arriba, o } \\
\text { no las dejan mover si han roto fuente así esté en cero } \\
\text { centímetros de dilatación y lo que argumentan es que } \\
\text { es la bioseguridad de la paciente, pero pues realmente } \\
\text { yo pienso que también es un poco de desconocimiento } \\
\text { y de pérdida de confianza en esa mujer, la debilitan } \\
\text { tanto, les da susto que se vaya a caer, entonces yo } \\
\text { pienso que como culturalmente o como nos educaron, } \\
\text { en los partos hospitalarios no fueron en movimiento } \\
\text { sino acostadas, pues se nos hace, que peligro tan } \\
\text { tremendo es una gestante caminando en fase activa } \\
\text { ino?" (Obstetra, medicina prepagada). }\end{array}$ \\
\hline Miedo & $\begin{array}{l}\text { Se presenta tanto en las mujeres como en } \\
\text { el personal. No solo incluye el miedo a } \\
\text { los riesgos, a la enfermedad y a la muer- } \\
\text { te, también a la violencia y al maltrato. } \\
\text { Está relacionado con el hecho de estar } \\
\text { prevenido, sentirse a la defensiva en los } \\
\text { servicios de salud y de ir a ellos solo si } \\
\text { es estrictamente necesario. }\end{array}$ & $\begin{array}{l}\text { "Yo siento que de pronto si tocara el tema con el obs- } \\
\text { tetra de decirle: 'no voy a ir a la programación de la } \\
\text { cesárea', sería como una guerra, no sé si incluso tenga } \\
\text { represalias conmigo, me da miedo eso, me ponga } \\
\text { una cita porque ya la otra semana tenemos el control } \\
\text { con él, y que me diga: 'no, ya, me toca programarte, } \\
\text { o sea, no podemos esperar más'; entonces ¿cómo le } \\
\text { voy a decir?" (Mujer ama de casa, profesional, plan } \\
\text { complementario). }\end{array}$ \\
\hline Obligatoriedad & $\begin{array}{l}\text { La concepción de derechos en el sistema } \\
\text { de salud se convierte en obligaciones } \\
\text { para las mujeres, que si no se cumplen } \\
\text { se plantean represalias como el regaño } \\
\text { o el castigo. }\end{array}$ & $\begin{array}{l}\text { "Si uno no va a citas que le toca taller, y que si no va } \\
\text { a taller no les dan citas nuevamente porque, pues, a } \\
\text { veces uno no tiene el tiempo para ir a esos talleres } \\
\text { cuando pierde las citas, y pues a veces uno no puede } \\
\text { asistir a las citas porque se le presentan inconvenientes, } \\
\text { y pues le ponen a uno esas tareas sin uno tener tiempo } \\
\text { ni nada, entonces digo que también deberían cambiar } \\
\text { eso" (Mujer ama de casa, régimen subsidiado). }\end{array}$ \\
\hline
\end{tabular}




\begin{tabular}{|c|c|c|}
\hline Código & Definición conceptual & Citas \\
\hline $\begin{array}{l}\text { Saber-Poder } \\
\text { de la posición } \\
\text { médica }\end{array}$ & $\begin{array}{l}\text { Los saberes de los galenos sobre el } \\
\text { cuerpo de las mujeres son considerados } \\
\text { un saber experto y autorizado que no } \\
\text { se cuestiona ni se pone en duda. En ese } \\
\text { sentido, las mujeres obedecen la auto- } \\
\text { ridad médica porque ellas no tienen el } \\
\text { conocimiento ni el reconocimiento que } \\
\text { los médicos tienen. }\end{array}$ & $\begin{array}{l}\text { "Si los médicos están diciendo que no es posible de } \\
\text { pronto la equivocada soy yo porque es que todo el } \\
\text { mundo lo dice y son personas que estudian para eso } \\
\text { o sea, como no creerles si están con especializaciones } \\
\text { precisamente y son especialistas en el tema entonces. } \\
\text { Que te digan que no, que está muy grande, pues ob- } \\
\text { viamente ya tú empiezas a dudar de que no es posible } \\
\text { el parto natural y no voy a insistir" (Mujer profesional, } \\
\text { ama de casa, plan complementario). }\end{array}$ \\
\hline $\begin{array}{l}\text { Riesgo y } \\
\text { bioseguridad }\end{array}$ & $\begin{array}{l}\text { Aspectos que justifican las prácticas me- } \\
\text { dicalizadas. Se visibilizan como verdades } \\
\text { absolutas, no se cuestionan y se impo- } \\
\text { nen para disminuir morbimortalidad } \\
\text { materno-infantil. }\end{array}$ & $\begin{array}{l}\text { "En una clínica que me dicen que por bioseguridad } \\
\text { del paciente no es permitida la movilidad de una } \\
\text { mujer en trabajo de parto a partir de la fase activa, } \\
\text { o sea de } 5 \text { centímetros de dilatación hacia arriba, o } \\
\text { no las dejan mover si han roto fuente así esté en cero } \\
\text { centímetros de dilatación y lo que argumentan es que } \\
\text { es la bioseguridad de la paciente, pero pues realmente } \\
\text { yo pienso que también es un poco de desconocimiento } \\
\text { y de pérdida de confianza en esa mujer, la debilitan } \\
\text { tanto, les da susto que se vaya a caer, entonces yo } \\
\text { pienso que como culturalmente o como nos educaron, } \\
\text { en los partos hospitalarios no fueron en movimiento } \\
\text { sino acostadas, pues se nos hace, que peligro tan } \\
\text { tremendo es una gestante caminando en fase activa } \\
\text { ¿no?" (Obstetra, medicina prepagada). }\end{array}$ \\
\hline Miedo & $\begin{array}{l}\text { Se presenta tanto en las mujeres como en } \\
\text { el personal. No solo incluye el miedo a } \\
\text { los riesgos, a la enfermedad y a la muer- } \\
\text { te, también a la violencia y al maltrato. } \\
\text { Está relacionado con el hecho de estar } \\
\text { prevenido, sentirse a la defensiva en los } \\
\text { servicios de salud y de ir a ellos solo si } \\
\text { es estrictamente necesario. }\end{array}$ & $\begin{array}{l}\text { "Yo siento que de pronto si tocara el tema con el obs- } \\
\text { tetra de decirle: 'no voy a ir a la programación de la } \\
\text { cesárea', sería como una guerra, no sé si incluso tenga } \\
\text { represalias conmigo, me da miedo eso, me ponga } \\
\text { una cita porque ya la otra semana tenemos el control } \\
\text { con él, y que me diga: 'no, ya, me toca programarte, } \\
\text { o sea, no podemos esperar más'; entonces ¿cómo le } \\
\text { voy a decir?” (Mujer ama de casa, profesional, plan } \\
\text { complementario). }\end{array}$ \\
\hline Obligatoriedad & $\begin{array}{l}\text { La concepción de derechos en el sistema } \\
\text { de salud se convierte en obligaciones } \\
\text { para las mujeres, que si no se cumplen } \\
\text { se plantean represalias como el regaño } \\
\text { o el castigo. }\end{array}$ & $\begin{array}{l}\text { "Si uno no va a citas que le toca taller, y que si no va } \\
\text { a taller no les dan citas nuevamente porque, pues, a } \\
\text { veces uno no tiene el tiempo para ir a esos talleres } \\
\text { cuando pierde las citas, y pues a veces uno no puede } \\
\text { asistir a las citas porque se le presentan inconvenientes, } \\
\text { y pues le ponen a uno esas tareas sin uno tener tiempo } \\
\text { ni nada, entonces digo que también deberían cambiar } \\
\text { eso" (Mujer ama de casa, régimen subsidiado). }\end{array}$ \\
\hline
\end{tabular}




\begin{tabular}{|c|c|c|}
\hline Código & Definición conceptual & Citas \\
\hline $\begin{array}{l}\text { Prácticas } \\
\text { medicalizadas } \\
\text { impuestas }\end{array}$ & $\begin{array}{l}\text { Existen, dada la visión del riesgo, la bi- } \\
\text { oseguridad y la obligatoriedad en condi- } \\
\text { ciones fisiológicas. Por ejemplo, tomar } \\
\text { vitaminas así las mujeres se sientan mal } \\
\text { con ellas o no sean necesarias, la induc- } \\
\text { ción médica del parto y su cadena de } \\
\text { medicalización, el ayuno prolongado en } \\
\text { el trabajo de parto, la cesárea, la medical- } \\
\text { ización neonatal relacionada con los pro- } \\
\text { cedimientos médicos del recién nacido } \\
\text { en el momento del nacimiento, la canali- } \\
\text { zación endovenosa y la monitoría fetal } \\
\text { permanente que impide la movilización } \\
\text { durante el trabajo de parto, la elección } \\
\text { de la posición del parto que rechaza las } \\
\text { posiciones verticales por bioseguridad, } \\
\text { la episiotomía, el control del pujo y los } \\
\text { tactos vaginales por horario que no son } \\
\text { necesarios en un parto natural. }\end{array}$ & $\begin{array}{l}\text { "Es doloroso arrastrarse de una camilla a la otra de la } \\
\text { sala de partos, de por sí que es horrible parir acostada, } \\
\text { yo quería ir de pie” (Mujer profesional, asalariada, } \\
\text { régimen contributivo) } \\
\text { "Ese parto es mi frustración pues no era el momento } \\
\text { de la inducción del parto porque, el cuerpo es sabio, } \\
\text { y pues nada, que todo estaba bien, y yo entiendo que } \\
\text { la cesárea es necesaria cuando hay un riesgo para } \\
\text { la mamá y el bebé. Uno entiende que hay razones } \\
\text { técnicas, o de la ciencia, pero yo no tenía ninguna } \\
\text { razón simplemente porque él bebé no bajaba, estando } \\
\text { yo acostada. Quedé como con esta sensación de no } \\
\text { haberle preguntado a otra persona si de pronto era } \\
\text { verdad, o él simplemente tenía afán porque tenía que } \\
\text { hacer la cirugía y ya, y bueno, ese fue el tema feo. } \\
\text { No sentí confianza en el obstetra, no le creí todo lo } \\
\text { que me dijo" (Mujer profesional, ama de casa, plan } \\
\text { complementario) }\end{array}$ \\
\hline $\begin{array}{l}\text { Alternativas } \\
\text { humanizadas } \\
\text { por fuera del } \\
\text { sistema }\end{array}$ & $\begin{array}{l}\text { Las prácticas medicalizadas obligan a } \\
\text { pagar alternativas por fuera del sistema } \\
\text { de salud como las doulas, las parteras y } \\
\text { los partos domiciliarios donde tienen } \\
\text { alternativas cuando el EPP es fisiológico. } \\
\text { Los derechos que buscan las mujeres } \\
\text { por fuera del sistema de salud son: } \\
\text { derecho al parto natural, derecho a que } \\
\text { el recién nacido no sea separado de la } \\
\text { madre en el momento del nacimiento, } \\
\text { derecho a disminuir el dolor, derecho a } \\
\text { la movilidad durante el trabajo de parto, } \\
\text { derecho a elegir la posición durante del } \\
\text { trabajo de parto, derecho a manifestar el } \\
\text { dolor, derecho a decidir el tipo de parto, } \\
\text { derecho a elegir la forma de alimentar el } \\
\text { bebé, derecho al acompañamiento por } \\
\text { el personal de salud, derecho a que sus } \\
\text { redes sociales participen en el proceso } \\
\text { de atención y derecho a la privacidad. }\end{array}$ & $\begin{array}{l}\text { "He pensado incluso que si no encuentro el apoyo del } \\
\text { sistema de salud, de pronto pagar aparte del sistema } \\
\text { y hacerlo aislada. Yo tengo un objetivo y un sueño y } \\
\text { creo que las mujeres estamos preparadas para eso y } \\
\text { creo que podemos. La doula me daba como esa se- } \\
\text { guridad y me decía: 'lo estás haciendo muy bien'. Ya } \\
\text { en el trabajo de parto fue importante aprender cómo } \\
\text { controlar el dolor. Se necesita tener las herramientas } \\
\text { para que no sea algo tortuoso ni tan sufrido porque } \\
\text { es un momento que se puede llegar a disfrutar. La } \\
\text { oxitocina se eleva con el placer, entonces es buscar } \\
\text { dentro de ese mismo nivel de dolor, empezar a iden- } \\
\text { tificar el placer de parir" (Mujer profesional, ama de } \\
\text { casa, plan complementario). }\end{array}$ \\
\hline
\end{tabular}




\begin{tabular}{|c|c|c|}
\hline Código & Definición conceptual & Citas \\
\hline $\begin{array}{l}\text { La medicali- } \\
\text { zación afecta } \\
\text { la salud }\end{array}$ & $\begin{array}{l}\text { Efectos secundarios de determinadas } \\
\text { prácticas institucionales que no son } \\
\text { visibles para las mujeres en los servicios } \\
\text { de salud. Un ejemplo de lo anterior } \\
\text { son los efectos secundarios de los pro- } \\
\text { cedimientos invasivos como la cesárea, } \\
\text { la anestesia epidural, o los diagnósticos } \\
\text { que requieren invadir la cavidad uterina. }\end{array}$ & $\begin{array}{l}\text { "Tome la decisión de tener otro concepto, de otro } \\
\text { médico, o sea pregunté si había la posibilidad porque } \\
\text { una amiga mía médica también ya había estado ahí } \\
\text { entonces con otra persona, a ver si había posibilidad } \\
\text { y la doctora tenía citas, entonces pues pedí con ella, a } \\
\text { ver qué otro concepto había, porque pues obviamente } \\
\text { no sé si por ser médica o no, pero en todo caso uno } \\
\text { no se queda como muy tranquilo, que le vayan a } \\
\text { empezar a hacer más exámenes, ella me advirtió que } \\
\text { de repente sí empezaba a subir la inmunoglobulina } \\
\text { lo que tocaba era sacar líquido, una amniocentesis, } \\
\text { y pues eso sí ya me preocupaba porque uno puede } \\
\text { hacer contracciones u otras cosas" (Mujer médica, } \\
\text { empresaria, medicina prepagada). }\end{array}$ \\
\hline $\begin{array}{l}\text { Mujer } \\
\text { como objeto }\end{array}$ & $\begin{array}{l}\text { Forma como es vista la mujer en los ser- } \\
\text { vicios de salud en medio de la vigilancia, } \\
\text { la cual se centra en los exámenes y en } \\
\text { el control del riesgo, desconociendo los } \\
\text { aspectos emocionales y sociales. }\end{array}$ & $\begin{array}{l}\text { "El ejercicio médico se ha vuelto así, '¿a qué viene y } \\
\text { qué quiere que le mande, cuántos días de incapacidad } \\
\text { quiere que le mande?', así es porque lo he visto en } \\
\text { mis compañeros, entonces se vuelve como como una } \\
\text { cosa de confección, de corte, una panadería que uno } \\
\text { mete al horno y saca. Entonces se ha perdido el amor } \\
\text { por la profesión, por lo que uno hace y eso hace que } \\
\text { a uno no le importa. Yo he encontrado patologías, he } \\
\text { encontrado enfermedades que son simplemente que } \\
\text { si alguien lo hubiera tocado se hubiera dado cuenta" } \\
\text { (Médica general, régimen subsidiado y contributivo). }\end{array}$ \\
\hline
\end{tabular}

público global” (37). La influencia de las organizaciones internacionales es tan fuerte que construye subjetividades en los trabajadores locales de salud, quienes tampoco se enfocan en las necesidades de la población, sino en las demandas internacionales (37) relacionadas con los objetivos del milenio de morbimortalidad materna, pero que no evalúan la calidad de la atención. Al respecto, en los datos de la OP de la presente investigación se dialogó con los trabajadores(as) de la salud participantes (tabla 2), quienes refirieron que los indicadores de mortalidad materno-infantil generan una presión sobre el personal y por eso su enfoque en el momento de la atención requiere estar basado en el riesgo (22).

Algunas de las estrategias de salud pública son de carácter obligatorio y generan acciones de vigi- lancia. Si la comunidad o el trabajador no realizan las actividades requeridas por la salud pública, se penaliza. Esta situación sucede en territorios donde las personas no tienen sus necesidades básicas satisfechas y hay déficit de insumos médicos. Este tipo de programas saludables provoca rechazo en la población y afecta los derechos ciudadanos (37). Lo anterior se puede observar en los resultados de la presente investigación (tabla 4, código "Obligatoriedad"), donde las mujeres tienen que disponer de tiempo extra y dinero para ir a talleres si no asisten a las consultas. En la OP se observó que algunos trabajadores de la salud del régimen subsidiado le explican a las mujeres que si "no asisten a las citas habrá consecuencias", pero no se especifica qué tipo de consecuencias. Igualmente, se observó que 
cuando las participantes no cumplen las órdenes médicas son regañadas y culpabilizadas por no ser "buenas madres" (22).

El déficit de calidad en la atención obliga a la población a pagar servicios privados de salud costosos (en continuo crecimiento) que no tienen regulación por parte del Estado. Las prácticas privadas en salud no siempre son de calidad, pues se formulan en el contexto del mercado (37). Lo anterior se puede visibilizar en la presente investigación (tabla 4, código "Alternativas humanizadas por fuera del sistema"), donde las mujeres especifican que existe mala calidad en la atención pues no se garantizan prácticas humanizadas del parto y necesitan pagar atención privada con doulas y parteras. Para las mujeres que no tienen conocimiento sobre el tema no es fácil elegir la mejor opción en el contexto del mercado (22).

En los datos de la OP también se apreció que las mujeres necesitaban pagar por alternativas diferentes a la medicalización, entre ellas las terapias tradicionales y alternativas que son valoradas positivamente por las participantes porque se tiene en cuenta su contexto cultural, social y emocional. Asimismo, las mujeres más pobres debían pagar por servicios de salud que son derechos como, por ejemplo, la atención de urgencias pediátricas. Para algunas mujeres del régimen subsidiado es más barato solucionar el problema en la farmacia del barrio, que someterse a barreras de acceso como las condiciones de la espera en los servicios de salud y el déficit de insumos médicos $(22,24)$. En la OP se observó de manera recurrente, en los itinerarios de las mujeres participantes del régimen subsidiado, el déficit de insumos. Por ejemplo, exámenes diagnósticos necesarios para identificar el riesgo del embarazo, los cuales no están disponibles oportunamente en el momento que las mujeres los necesitan, así como algunos reactivos de tamizaje de toxoplasmosis, y algunas ecografías cubiertas por la seguridad social (22).

Scheper-Hughes analiza que la problemática es reproducida por la burocracia administrativa de las instituciones y el personal de salud, que desarrollan un discurso altamente autorizado y especializado que tiene poder sobre el actuar de la comunidad. Develar qué hay detrás del lenguaje que legitima las injusticias es fundamental en los procesos de investigación (38). Al respecto, en la OP de la presente investigación se reflexiona sobre lo que hay detrás del concepto del riesgo. En el contexto de los servicios de salud este es visto de una manera superficial, parece ser un asunto técnico, estadístico, probabilístico y naturalizado. Pero el concepto en sí no deja ver la incertidumbre que lo acaricia, ni cómo se instrumentaliza para tomar decisiones sobre el cuerpo de las mujeres. Asimismo, detrás del concepto del riesgo están también los discursos del capitalismo, que en su afán de producción económica se articulan con la biomedicina para medicalizar los cuerpos de las mujeres sanas, incurriendo en violencia obstétrica (22).

La medicalización invisibiliza los orígenes políticos de las problemáticas sociales (38). Al respecto, en la OP de la presente investigación se reflexiona acerca de cómo medicalizar oculta a las mujeres el déficit estructural del sistema de salud: el hecho de parir rápido para descongestionar el servicio no es visible para las mujeres, porque la responsabilidad de la violencia obstétrica recae sobre el personal de salud (22).

Tanto usuarios como personal de salud "comparten” la ideología del sistema de salud y político. Trabajan y se relacionan en las instituciones de salud al parecer "voluntariamente". Así las instituciones reproduzcan la violencia, los humanos participan de ella y la legitiman (38). Lo anterior se puede visibilizar en la presente investigación (tabla 4, código "Saber-Poder de la posición médica").

Las prácticas institucionales en salud han sido analizadas previamente desde las teorías del género y feminista $(1,8,9,12,13,23)$. Para el caso de la presente investigación, este tipo de violencias se intensifican en el contexto del capitalismo global que afecta el funcionamiento del sistema de salud colombiano (22). 
Respecto a las limitaciones operativas del trabajo de campo y metodológicas se aclara que esta investigación no desarrolla un modelo comparativo en investigación cualitativa, el cual tiene un carácter controlado, selección rigurosa de casos, sistematización con enfoque matemático y generalización a la población de estudio. Estos modelos comparativos se ubican epistemológicamente en un paradigma positivista (61), diferente al expuesto en la presente investigación.

A pesar de lo anterior, la pregunta de investigación incluye la categoría clase social que permite hacer comparaciones en un método descriptivo como la etnografía. La clase social es una categoría analítica que permite comparar grupos de personas según lo expuesto en los resultados. Lo anterior buscó darle sentido a los datos, lo cual es coherente con la investigación cualitativa en general (62). Al respecto, la comparación que se realiza en la presente investigación, es un "recurso cognitivo inherente a todo proceso de intelección" (61). Se realiza "contrastación como auxiliar en la producción de conocimiento" (61). Esto es diferente a los modelos comparativos donde se recurre a la comparación de manera sistemática (61), ajena al diseño metodológico de la presente investigación.

El método de la etnografía crítica $(38,63,64)$ es una herramienta fundamental en salud pública que permite la construcción de proyectos de investigación con acercamientos a la realidad integrales, éticos y que buscan el beneficio de los colectivos. Puede incluir otras herramientas como la epidemiología y la estadística que, a su vez, se benefician de la reflexión que aporta el método y da cuenta de aspectos estructurales relevantes para comprender la realidad.

Los sesgos del estudio, reconocidos en la investigación cuantitativa, no aplican para la investigación cualitativa. Por ejemplo, el hecho de que el personal de salud que acompaña a las mujeres no quisiera participar fue discutido por el grupo de investigación como un resultado significativo que indaga sobre las dificultades que podría afrontar el personal en el proceso de atención.

\section{CONCLUSIÓN}

Respondiendo a la pregunta planteada se concluye que existen desigualdades según la clase social en las prácticas institucionales en salud que se realizan en las mujeres en embarazo, parto y posparto. Estas desigualdades se acentúan en las mujeres con una clase social menos aventajada, en los siguientes aspectos: déficit institucional, tiempo de contacto en las citas, prácticas medicalizadas impuestas, derecho a prácticas humanizadas, y obligatoriedad en los servicios.

Es importante promocionar una visión crítica en el personal de salud frente a la formación médica y el funcionamiento del sistema de salud. La construcción de competencias ciudadanas en estos aspectos podría ser una herramienta para cambiar colectivamente el funcionamiento del sistema de salud y garantizar los derechos de las mujeres

\section{AGRADECIMIENTOS}

A Colciencias y la Convocatoria de mínima cuantía de la Universidad CES de Medellín por la financiación. A las mujeres y el personal de salud que participaron en la investigación. A la Fundación Arka, Organización Apapachoa, Movimiento Nacional por la Salud Sexual y Reproductiva en Colombia, Tribu Criarte, Secretaría de Salud de Bogotá. A Marcelo Amable, Alfredo Maya y Mónica Sáenz por sus aportes desde las ciencias sociales.

\section{FINANCIACIÓN}

Beca doctorado nacional Colciencias, Convocatoria 647-2014 y Convocatoria de pequeña cuantía de la Universidad CES, Medellín (Colombia).

\section{REFERENCIAS}

1. Fernández S. La violencia de género en las prácticas institucionales de salud: afectaciones del derecho a la salud y a las condiciones de trabajo en salud. Rev Gerenc Polit Salud. 2007;6(12):52-76.

2. Santiago RV, Monreal LA, Rojas Carmona A, Domínguez MS. "If we're here, it's only because we have no money...". Discrimination and violence in Mexican 
maternity wards. BMC pregnancy and childbirth. 2018;18(1):244. https://doi.org/10.1186/s12884018-1897-8

3. Organización Mundial de la Salud (OMS). Recomendaciones de la OMS para los cuidados durante el parto, para una experiencia de parto positiva. Transformar la atención a mujeres y neonatos para mejorar su salud y bienestar. Ginebra: OMS; 2018.

4. Al Adib Mendiri M, Ibáñez-Bernáldez M, CasadoBlanco M, Santos-Redondo P. La violencia obstétrica: un fenómeno vinculado a la violación de los derechos elementales de la mujer. Med Leg Costa Rica. 2017;34:104-11.

5. OMS. Prevención y erradicación de la falta de respeto y el maltrato durante la atención del parto en centros de salud. Ginebra: OMS; 2014. Disponible en: https:// apps.who.int/iris/bitstream/handle/10665/134590/ WHO_RHR_14.23_spa.pdf;jsessionid $=8 \mathrm{D} 5556 \mathrm{D}$ 17EF46062AA6DDB21F34094F4 sequence $=1$.

6. Sadler M, Santos MJ, Ruiz-Berdún D, Rojas GL, Skoko E, Gillen P, et al. Moving beyond disrespect and abuse: Addressing the structural dimensions of obstetric violence. Reprod Health Matters. 2016;24(47):47-55. https://doi.org/10.1016/j.rhm.2016.04.002

7. Downe S, Lawrie TA, Finlayson K, Oladapo OT. Effectiveness of respectful care policies for women using routine intrapartum services: A systematic review. Reprod health. 2018;15(1):23. https://doi.org/10.1186/ s12978-018-0466-y

8. Bedoya-Ruiz LA, Agudelo-Suárez AA, Restrepo-Ochoa DA. Mujeres en embarazo, parto y posparto: una mirada desde el pensamiento feminista. Rev Peru Med Exp Salud Publica. 2020;37(1):142-7. https://doi. org/10.17843/rpmesp.2020.371.4981.

9. Monroy MSA. El continuo ginecobs-tétrico. Experiencias de violencia vividas por mujeres gestantes en servicios de salud en Bogotá. Bogotá: Escuela de Estudios de Género, Universidad Nacional de Colombia; 2012.

10. Colón IC. Sentimientos, memorias y experiencias de las mujeres en trabajo de parto. El caso de centros hospitalarios en Cartagena. Cartagena: Universidad de Cartagena y Universidad Nacional de Colombia; 2008.
11. Mejía-Merino CM, Faneyra-Zapata L, Molina-Berrío DP, Arango-Urrea JD. Dehumanization during delivery: Meanings and experiences of women cared for in the Medellín public network. Invest Educ Enferm. 2018;36(1):e03. https://doi.org/10.17533/udea.iee. v36n1e03

12. Rocha-Acero ML, Socarrás-Ronderos F, Rubio-León DC. Prácticas de atención del parto en una institución prestadora de servicios de salud en la ciudad de Bogotá. Rev Fac Nac Salud Pública. 2019;37(1).

13. Vallana-Sala VV. Parirás con dolor, lo embarazoso de la práctica obs-tétrica: discursos y prácticas que naturalizan la violencia obstétrica en Bogotá. Bogotá: Facultad de Ciencias Sociales, Pontificia Universidad Javeriana; 2016.

14. Jojoa-Tobar E, Cuchumbe-Sánchez YD, LedesmaRengifo JB, Muñoz-Mosquera MC, Suárez Bravo JP. Violencia obstétrica: haciendo visible lo invisible. Rev Univ Ind Santander Salud. 2019;51(2):136-47. https://doi.org/10.18273/revsal.v51n2-2019006

15. Briceño-Morales X, Enciso-Chaves LV, YepesDelgado CE. Neither medicine nor health care staff members are violent by nature: Obstetric violence from an interactionist perspective. Qual Health Res. 2018;28(8):1308-19. https://doi. org/10.1177/1049732318763351

16. Breilh J. Replanteo del método epidemiológico En: Breilh J, editor. Crítica a la interpretación capitalista de la Epidemiología. Un ensayo de desmitificación del proceso de salud y enfermedad. México: Universidad Autonoma Metropolitana; 1977.

17. Breilh J. Breve recopilación sobre operacionalización de la clase social para encuestas en la investigación social. Quito: Centro de Estudios y Asesoría en Salud (CEAS); 1989. p. 1-12.

18. OMS. Determinantes e inequidades en salud. Ginebra: OMS; 2012 Disponible en: http://www.paho.org/ saludenlasamericas/index.php?option $=$ com_conten t\&view=article\&id=58\&Itemid=165\&lang=es.

19. Instituto Nacional de Salud, Ministerio de Salud de Colombia. Clase social y salud. Bogotá: Instituto Nacional de salud, Observatorio Nacional de Salud, Ministerio de Salud de Colombia; 2016. Disponible 
en: https://www.ins.gov.co/Direcciones/ONS/Informes/8.\%20Clase\%20Social\%20y\%20Salud.pdf.

20. Benach J, Amable M. Las clases sociales y la pobreza. Gaceta Sanitaria. 2004;18:16-23. https://doi. org/10.1157/13062246

21. Bedoya-Ruiz LA, Agudelo-Suárez AA. Relación de las mujeres en embarazo parto y postparto (EPP) con los servicios de salud según la clase social. Rev Gerenc Polít Salud. 2019;18(36). https://doi.org/10.11144/ Javeriana.rgsp18-36.rmep

22. Bedoya-Ruiz LA. Configuración de la relación de las mujeres en embarazo, parto y postparto con los servicios de salud en diferentes niveles de atención según la clase social. Bogotá (Colombia). Medellín: Escuela de Graduados, Doctorado Salud Pública, Universidad CES; 2020. Disponible en: https://repository.ces.edu. co/handle/10946/4450.

23. Bedoya-Ruiz LA, Agudelo-Suárez AA, Restrepo-Ochoa DA. Relaciones que establecen las mujeres durante el embarazo, parto y posparto con el personal de salud según clase social en Bogotá: estudio cualitativo. Rev Peru Med Exp Salud Publica. 2020;37(1):7-16. https://doi.org/0.17843/rpmesp.2020.371.4963

24. Bedoya-Ruiz LA, Agudelo-Suárez AA, Restrepo-Ochoa DA. Acceso de mujeres en embarazo, parto y post parto a servicios de salud según clase social. Salud UIS. 2020;52(3):285-94.

25. Kincheloe J, McLaren P. Replanteo de la teoría crítica y de la investigación cualitativa. En: Denzin NK, Lincoln YS, editors. Manual de investigación cualitativa. Paradigmas y perspectivas en disputa. II vol. Barcelona: Gedisa; 2012. p. 241-91.

26. Menéndez EL. El punto de vista del actor: homogeneidad, diferencia e historicidad. En: Menéndez EL, editor. La parte negada de la cultura: relativismo, diferencias y racismo. Barcelona: Edicions Bellaterra; 2002. p. 291-365.

27. Galeano ME. Diseño de proyectos en la investigación cualitativa. Bogotá: Fondo Editorial Universidad EAFIT; 2004.

28. Breilh J. Las categorías causalidad y clase social como elementos de la ideología epidemiológica En: Breilh J, editor. Crítica a la interpretación capitalista de la
Epidemiología. Un ensayo de desmitificación del proceso de salud y enfermedad. México: Universidad Autonoma Metropolitana; 1977. p. 78-90.

29. Restrepo-Ochoa DA. Vigencia de la categoría clase social en salud pública. En: Estrada MJH, editor. Teoría crítica de la sociedad y salud pública. Bogotá: Universidad Nacional de Colombia, Universidad de Antioquia; 2011. p. 134-44.

30. Fontana A, Frey JH. La entrevista. En: Denzin N, Lincoln Y, editors. Manual de Investigación Cualitativa. Métodos de recolección y análisis de datos. Barcelona: Gedisa; 2015. p. 140-89.

31. Foucault M. Historia de la medicalización. Educ Med Salud. 1977;11(1):2-25.

32. Restrepo LJ. Parteras, comadronas y médicos: la instauración de la obstetricia en Medellín 1870-1920. Rev Univ Pontif Boliv. 2015;44(140):10.

33. Evens TMS, Handelman D. Introduction: The Ethnographic Praxis of the Theory of Practice. Social Analysis. 2005;49(3):1-11. https://doi. org/10.3167/015597705780275075

34. Strauss A, Corbin J. Bases de la investigación cualitativa. Técnicas y procedimientos para desarrollar la teoría fundamentada. Medellín: Editorial Universidad de Antioquia, Facultad de Enfermería de la Universidad de Antioquia; 2002.

35. Mendizábal N. Los componenentes del diseño flexible en la investigación cualitativa. En: de Gialdino V, editor. Estrategias de investigación cualitativa. Barcelona: Gedisa; 2006. p. 65-103.

36. Tong A, Sainsbury P, Craig J. Consolidated criteria for reporting qualitative research (COREQ): a 32item checklist for interviews and focus groups. Int J Qual Health Care. 2007;19(6):349-57. https://doi. org/10.1093/intqhe/mzm042

37. Das V. Bien público, ética y vida cotidiana: más allá de los límites de la bioética. En: Das V, editor. Violencia, cuerpo y lenguaje. Ciudad de México: Umbrales, Fondo de Cultura Economica; 2016.

38. Scheper-Hughes N. La muerte sin llanto. Violencia y vida cotidiana en Brasil. Barcelona: Ariel; 1997.

39. Oróstegui R, Bermúdez C, Linares A, Rueda M, Gonzales J, Arévalo T. Informe de calidad de vida de 
Bogotá. Bogotá: Programa "Bogotá cómo vamos"; 2017. Disponible en: http://www.bogotacomovamos. org/documentos/informe-de-calidad-de-vida-enbogota-en-2017/.

40. De Groote T, De Paepe P, Unger J-P. Las consecuencias del neoliberalismo Colombia: prueba in vivo de la privatización del sector salud en países en desarrollo. Rev Fac Nal Salud Pública. 2007;25:106-17.

41. Borrero RYE. Derecho a la salud, justicia sanitaria y globalización: un debate pendiente. Rev Fac Nal Salud Pública. 2011;29:299-307.

42. Labonté R, Schrecker T. Globalization and social determinants of health: The role of the global marketplace (part 2 of 3). Glob Health. 2007;3(6). https:// doi.org/10.1186/1744-8603-3-6

43. Abadía C, Pinilla MY, Ariza K, Ruiz HC. Neoliberalismo en salud: la tortura de trabajadoras y trabajadores del Instituto Materno Infantil de Bogotá. Rev Salud Pública. 2012;14(1s):14. https://doi.org/10.1590/ S0124-00642012000700003

44. Pinilla MY, Abadía CE. Hospital San Juan de Dios: actor y víctima de las políticas públicas en Colombia. Rev Peru Med Exp Salud Pública. 2017;34(2):287-92. https://doi.org/10.17843/rpmesp.2017.342.2888

45. Departamento Administrativo Nacional de Estadística (DANE). Cuadro 10. Nacimientos por tipo de parto, según departamento de residencia de la madre y multiplicidad del embarazo. Bogotá: DANE; 2016. Disponible en: https://www.dane.gov.co/index. php?option $=$ com_content\&view $=$ article $\& i d=1246$ \&itemid $=73$.

46. Ministerio de Salud de Colombia. Estudios sectoriales. Atlas de variaciones geográficas en salud de Colombia. Bogotá: Ministerio de Salud de Colombia; 2015.

47. Organización Mundial de la Salud (OMS). Declaración de la OMS sobre tasas de cesárea. Ginebra: OMS; 2015.

48. Molina G, Weiser TG, Lipsitz SR, Esquivel MM, Uribe-Leitz T, Azad T, et al. Relationship between cesarean delivery rate and maternal and neonatal mortality. JAMA. 2015;314(21):2263-70. https://doi. org/10.1001/jama.2015.15553
49. Integrantes del Consenso de la Federación Colombiana de Obstetricia y Ginecología (FECOLSOG), Federación Colombiana de Perinatología. Racionalización del uso de la cesárea en Colombia. Rev Col Obstet Ginecol. 2014;65(2):139-51. https://doi. org/10.18597/rcog.62

50. Asociación Colombiana de Hospitales y Clínicas. La realidad financiera de los hospitales y clínicas. Bogotá: Asociación Colombiana de Hospitales y Clínicas; 2017. Disponible en: http://achc.org.co/ wp-content/uploads/2018/01/Realidad-FinancieraHospitales.pdf.

51. Ministerio de Salud y Protección Social, Dirección de Epidemiología y Demografía. Análisis de Situación de Salud (ASIS) Colombia, 2017. Bogotá: Ministerio de Salud y Protección Social; 2018.

52. Organización Mundial de la Salud (OMS). Estadísticas sanitarias mundiales. Ginebra: OMS; 2012.

53. Bejarano-Daza JE, Hernández-Losada DF. Fallas del mercado de salud colombiano. Rev Fac Med. 2017; 65(1):107-13. https://doi.org/10.15446/revfacmed. v65n 1.57454

54. Centro de investigaciones y consultorías. Grupo de Economía de la Salud. Análisis del costo de la atención del parto en Medellín. Medellín: Universidad de Antioquia; 2015.

55. Secretaría Distrital de Salud de Bogotá, Dirección de Planeación Sectorial, Subdirección de Vigilancia en Salud Pública, Grupo Análisis de Condiciones Calidad de Vida Salud y Enfermedad. Documento de Análisis de situación de salud con el modelo de los determinantes sociales de salud para el Distrito Capital. Bogotá: Secretaría Distrital de Salud de Bogotá; 2017.

56. Ramírez HS. Calidad de la atención en salud. Prácticas y representaciones sociales en las poblaciones quechua y aymara del antiplano boliviano. La Paz: OPS; 2010.

57. Ministerio de Salud de Colombia. Informe Nacional de Calidad de la Atención en Salud 2015. Bogotá: Ministerio de Salud de Colombia; 2015.

58. Ministerio de Salud de Colombia. Política de Atención Integral en Salud. Bogotá: Ministerio de Salud de Colombia; 2016. 
59. Opinión y Salud. Polémica por proyecto de ley que sanciona la violencia obstétrica. Opinión\&Salud.com Revista digital; 2017. Disponible en: https://www. opinionysalud.com/2018/04/30/polemica-proyectoley-sanciona-la-violencia-obstetrica/.

60. Uribe BDM, Viveros ML. Modelo de atención en salud “doulas”, para mejorar la calidad del cuidado perinatal en instituciones de primer nivel de atención en Bogotá. Cuadernos Latinoamericanos de Administración. 2009;V(9):95-119.

61. Ariza M, Gandini L. El análisis comparativo cualitativo como estrategia metodológica. En: Ariza M, Gandini L, editores. Métodos cualitativos y su aplicación empírica. Por los caminos de la investigación sobre migración internacional. Ciudad de México: Universidad Nacional Autónoma de México; 2012.

62. Denzin NK, Lincoln YS. Las estrategias de investigación cualitativa: Manual de investigación cualitativa. Barcelona: Gedisa; 2012.

63. Osorio-Carranza RM. Entender y atender la enfermedad. Los saberes maternos frente a los padecimientos infantiles. México DF: Instituto Nacional Indigenista/ Centro de Investigaciones y Estudios Superiores en Antropología Social; 2000.

64. Martínez HA. Antropología médica: teorías sobre la cultura, el poder y la enfermedad. Bogotá: Anthropos; 2008. Tabla 1. CarTabla 3. Códigos de la categoría: El mercado regula la salud 